\title{
Note
}

\section{ARTIFICIAL INTELLIGENCE AND SUI GENERIS RIGHT: A PERSPECTIVE FOR COPYRIGHT IN UKRAINE?}

\author{
Liubov Maidanyk \\ LiubovMaidanyk@univ.net.ua \\ https://orcid.org/0000-0002-1794-4513
}

Summary: 1. Introduction. - 2. Intellectual Property Right Protection for Al-generated Objects. - 3. Ukrainian Legal Policy Propositions Relevant to Al-generated Objects. - 4. Concluding Remarks.

To cite this note: L Maidanyk 'Artificial Intelligence and Sui Generis Right: A Perspective for Copyright of Ukraine? 2021 3(11) Access to Justice in Eastern Europe 144-154. D0I: 10.33327/AJEE-18-4.3-n000076

To link to this note: https://doi.org/10.33327/AJEE-18-4.3-n000076

Submitted on 09 Apr 2021 / Revised 21 May 2021 / Revised 23 June 2021 / Approved 26 Jul 2021 /

Published online: 02 Aug $2021 \quad$ View data

Submit your article to Access to Justice in Eastern Europe

\section{CONFLICTS OF INTEREST}

The author declares no conflict of interest of relevance to this topic. Although the author serves at same institution as one of the editors of AJEE, which may cause a potential conflict or the perception of bias, the final decisions for the publication of this article was handled by the editors, including choice of peer reviewers, and Editorial Board Members, who are not affiliated to the same institution.

\section{DISCLAIMER}

The opinions expressed in this note are those of the author and do not reflect the opinions of the state body or any bodies or persons who may benefit.

\section{ACKNOWLEDGEMENT}

The author would like to express her gratitude to the reviewers for their remarks and recommendations, which allowed her to improve the manuscript, and to the editors.

\section{CONTRIBUTOR}

The author was the sole contributor to the intellectual discussion underlying this paper, writing, and translating, and accepts responsibility for the content and interpretation. 


\title{
ARTIFICIAL INTELLIGENCE AND SUI GENERIS RIGHT: A PERSPECTIVE FOR COPYRIGHT IN UKRAINE?
}

\author{
Maidanyk Liubov \\ PhD (Law), Assoc. Prof., Law School, \\ Taras Shevchenko National University of Kyiv, Ukraine \\ LiubovMaidanyk@univ.net.ua \\ https://orcid.org/0000-0002-1794-4513
}

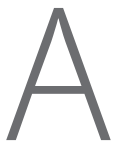

bstract This note explores the current state of and perspectives on the legal qualification of artificial intelligence (AI) outputs in Ukrainian copyright. The possible legal protection for AI-generated objects by granting sui generis intellectual property rights will be examined. As will be shown, AI remains a very challenging subject matter for legal regulation. This article seeks to identify the pros and cons of proposals in the Draft Law of Ukraine 'On copyright and related rights' on sui generis right relative to AI-generated objects. A comparative analysis of the EU Database Directive provisions is conducted regarding sui generis right to non-original databases. Investment theory will be considered as the only justification for a sui generis right protection of AI outputs aimed at the protection of substantial investments. The special criteria identifying the scope of the substantial investments in computer-generated objects are unclear in the Draft Law of Ukraine 'On copyright and related rights'. The proposed provisions are considered premature since they cover the concept of fully autonomous AI. The article concludes that the adoption of the proposed provisions may lead to excessive legal protection, as a special category of protected object is not identified.

Keywords: AI-generated object, copyright, sui generis right

\section{INTRODUCTION}

Changes in the socio-economic situation in a certain country inevitably entail changes in legal approaches to established concepts. After years of debate and various legislative experiments on the national level, computer programs have taken their place among objects protected by copyright subject matter at the international level. Today, the main technical challenge to be resolved by legal means is artificial intelligence (hereinafter, AI). The International Data Corporation predicts that by 2024, the AI market, including software, hardware, and services, is expected to reach $\$ 500$ billion. ${ }^{1}$ AI has become firmly embedded in our everyday life, including in creative industries. Currently, AI-related technologies are often used in content creation, information analysis, music production, and post-production of audio-visual works. ${ }^{2}$ It is hard to disagree with Andrew $\mathrm{Ng}$ that 'AI is the new electricity, ${ }^{3}$ a statement that raises a growing number of legal issues requiring in-depth analysis.

\footnotetext{
1 'IDC Forecasts Improved Growth for Global AI Market in 2021' (IDC.com 23 February 2021) <https:// www.idc.com/getdoc.jsp?containerId=prUS47482321> accessed 9 April 2021.

2 See N Anantrasirichai, D Bull, Artificial Intelligence in the Creative Industries: A Review (2020).

3 Andrew Ng, 'AI is the new electricity'. AI Frontiers Conference (2017).
} 
Today's main legal challenge is to evaluate autonomous computer systems generating new objects that may be subject to copyright, with this stipulation - that there is the absence of a human in the process of creation. For decades, the droit dateur system of copyright has maintained the position that the author can only be an individual because the process is characterised by creativity, which has originality as the main prerequisite. In the absence of these criteria, copyright cannot protect an object, so moral and economic rights do not occur. This approach forms an incentive for the author to pursue further creative activity. This anthropocentric approach has always been based on the protection and safeguarding of the rights of the individual, but the modern world has shifted from the views that were formed in the days of Victor Hugo. Recently, the leader of the famous Ukrainian music band 'Okean Elzy', Svyatoslav Vakarchuk, said that their latest song, 'Without you, I'm not here', was created by AI based on previous works of the band. ${ }^{4}$

This raises several practical issues related to the validity of copyright in music and the poetry of such a musical work: the need to obtain permission for performance; the possibility of collective management; the use of music and words by third parties. These and other questions are only a small part of the legal uncertainty of the new technological world in which we already live because there is no certainty as to who created the song: a human or an AI? Today, AI is used in various creative fields, for example, in painting and in translating literary works. This means that while we still have writers, musicians, artists, and game designers in charge of the creative process, a large number of tasks, particularly mechanical tasks, might be given to machines. ${ }^{5}$

At the end of 2020, the European Parliament issued Resolution 2020/2015(INI) on Intellectual Property Rights for the development of Artificial Intelligence Technologies. ${ }^{6}$ The Resolution distinguishes human-assisted and fully autonomous AI-outputs - 'AI-generated creations'. In this respect, the parliament is adamant about the legal personality of AI technologies and points to the possible negative impact on incentives for human creators. At the same time, legal challenges to the regulation of fully autonomous AI outputs are anticipated.

To conduct the present research, this paper will analyse different approaches to defining AI and the notion of authorship in relation to it. The paper will identify trends in the practice of intellectual property law protection of AI-based on individual decisions of Chinese courts and EU patent offices. In addition, a comparative analysis of current legislative regulation in the EU, the USA, and the UK will be carried out to assess the Ukrainian legislative initiative to protect AI outputs by sui generis right. This, together with a review of scientific thought on AI, will enable the author to make a modest attempt to assess and predict at an early stage the success of establishing a sui generis right for AI outputs.

\section{INTELLECTUAL PROPERTY RIGHT PROTECTION FOR AI-GENERATED OBJECT}

Research and legal regulation will not forge ahead without defining the main characteristics of AI systems. For the purposes of this study, the various definitions of AI will be considered in the context of possible application to the legal policy framework.

4 'Vakarchuk claimed that song "Without you, I'm not here" was written by artificial intelligence' (Thevillage.com.ua, 16 February 2021) <https:/www.the-village.com.ua/village/culture/culture-news/307755vakarchuk-zayaviv-scho-pisnyu-bez-tebe-mene-nema-napisav-shtuchniy-intelekt?fbclid=IwAR2j6EtGh KQxSyTPWqFdnpWXICOJSJ9gAnUl3qz4gSqufRarmGLnmy7949c> accessed 5 April 2021.

$5 \quad$ A Guadamuz, 'Do Androids Dream of Electric Copyright?' (2017) IPQ 169.

6 European Parliament resolution of 20 October 2020 on intellectual property rights for the development of artificial intelligence technologies (2020/2015(INI)). 
The understanding of AI given in the most recent European Parliament resolution on $\mathrm{AI}^{7}$ may define the concept in a further legal framework. It links AI with intelligence and autonomy, which are generally accepted to be core characteristics; yet, there may be different understandings of these concepts. The Resolution defines an 'AI system' as 'a system that ... displays behaviour simulating intelligence by, inter alia, collecting and processing data, analysing and interpreting its environment, and by taking action, with some degree of autonomy'. In this regard, it is worth noting the position of Gerald Spindler that AI is not 'intelligent' in a legal sense and cannot be compared to a human will. ${ }^{8}$ At the same time, the parliament clearly states that any required changes in the existing legal framework should start with the clarification that AI systems have neither legal personality nor human conscience and that their sole task is to serve humanity. ${ }^{9}$ A. Ramahlo very aptly interprets J. Copeland's definition of AI as machines, implying human-type behaviour in this context, in the sense that it means actions performed by computers that require intelligence when performed by humans. ${ }^{10}$ In this sense, the human will involves the independent (autonomous) setting and modification of goals. The parliament defines 'autonomous' as an AI system that operates by interpreting certain input and using a set of predetermined instructions, without being limited to such instructions, despite the system's behaviour being constrained by and targeted at fulfilling the goal it was given and other relevant design choices made by its developer. That legal framework on AI, which includes intellectual property rights, will remain its anthropocentric fundamentals.

However, a generalised understanding of AI, which includes potential future developments, has also been proposed among scholars. P. Morhat identifies AI as a fully or partially autonomous self-organising computer-hardware (virtual) or (cyber-physical), including (bio-cybernetic), system (unit) that is not alive in the biological sense but endowed with appropriate mathematical software and software-synthesised (emulated) abilities and capabilities. ${ }^{11}$ With this definition, the author tried to cover the current and future state of AI, at least as we can imagine it based on the information currently available. As we understand it, any attempt to define something that does not yet exist is futuristic. However, this definition is valuable because it may prepare us for legal uncertainty in the future.

Since AI has no common academic definition, it can be deceiving rather than informative to evoke one's own. AI technology is in a constant state of development, and the definition only captures the process at a certain stage. Furthermore, according to a thorough analysis conducted by P. Wang, there is no correct working definition of AI, as each of them has theoretical and practical values. ${ }^{12}$ Some scholars have taken the position that the definition of AI under today's conditions is inappropriate and confusing. ${ }^{13}$ We agree with the last position since, as various types of AI have been classified, namely, reactive machines, limited

7 European Parliament Resolution of 20 January 2021 on Artificial Intelligence: Questions of interpretation and application of international law in so far as the EU is affected in the areas of civil and military uses and of state authority outside the scope of criminal justice (2020/2013(INI)).

8 G Spindler, 'Copyright Law and Artificial Intelligence' (2019) IIC 50, 1049-1051 <https://doi. org/10.1007/s40319-019-00879-w>.

9 European Parliament Resolution of 20 October 2020 with recommendations to the Commission on a civil liability regime for artificial intelligence (2020/2014(INL)).

10 A Ramalho, 'Will Robots Rule the (Artistic) World? A Proposed Model for the Legal Status of Creations by Artificial Intelligence Systems' (2017) 21 Journal of Internet Law 12.

11 PM Morhat, 'The Legal Personality of Artificial Intelligence in Intellectual Property Law: Civil Law Issues' (Dr. Sc. (Law) thesis, Russian State Intellectual Property Academy 2018).

12 P Wang, 'On Defining Artificial Intelligence' (2019) 10 (2) Journal of Artificial General Intelligence 1-37. doi: 10.2478/jagi-2019-0002.

13 J-A Lee, K-C Liu, R Hilty (eds), Artificial Intelligence \& Intellectual Property (Oxford University Press 2021). 
memory, the theory of mind, and self-awareness, ${ }^{14}$ it is hard to form the universal definition of AI. An additional complication is that some types of AI do not exist yet, such as the theory of mind and self-awareness machines. Thus, it is hard to be entirely prognostic when considering the development of future technology and its interaction with society.

AI-generated objects, according to their form of expression, can be covered by intellectual property rights, which brings into question notions of a 'creator' from the point of originality. If we compare the cognitive functions, the difference between machine and human efforts at executing the same algorithms is that the quality of the result depends on the quantity of data being processed. A computer system can process much larger amounts of data in less time than any unaided human is capable of achieving. ${ }^{15}$ For example, in an experiment conducted by a team of highly qualified lawyers and an AI named Law Geex, the latter won. It took only 26 seconds for the AI to define all the inconsistencies in a non-disclosure agreement in comparison with 92 minutes for the human team. ${ }^{16}$ Although at first glance, humans could not have won this competition, it was still a human who determined the main aim and preferences of the task. Thus, the AI acted for the benefit of human-determined objectives without the awareness and ability to change this. This experiment, which was conducted mostly for fun, does not reflect the low intellectual abilities of humans but rather creates more space for performing truly creative and priority tasks.

The question of authorship is also closely linked to the requirement of originality. Both EU and Ukrainian law stipulate that work must be original to be copywritten. But does this necessarily require a human as an author? According to Eva-Maria Painer v. Standard Verlags $\mathrm{GmbH}$ and Others, only a person can fulfil the necessary requirements: making various creative choices and stamping the work with a 'personal touch' reflecting a personality. ${ }^{17}$ A similar position on copyright in US law can be seen through an analysis of law enforcement practices. For example, in the famous Naruto v. Slater (Monkey Selfie) case, the court has repeatedly related the concept of a 'creator' to humans, thereby denying the possibility of an animal creator. ${ }^{18}$ The Compendium of US Copyright Office Practices ${ }^{19}$ also hints at the inadmissibility of non-personal authorship, which, although recommendatory in nature, helps to confirm such a conclusion. It is stated that to qualify as a work of 'authorship', a work must be created by a human being. Thus, the Office will not register works produced by a machine or mere mechanical process that operates randomly or automatically without any creative input or intervention from a human author. The provision of Compendium is based on the case Burrow-Giles Lithographic Co. ${ }^{20}$

Legal research on $\mathrm{AI}$ is often conducted for AI tools and AI output. Because of the personal nature of this type of protection, there is no such thing as non-human intellectual property

14 A Hintze, 'Understanding the Four Types of Artificial Intelligence', Cloud and Computing (2016) $<$ https://www.govtech.com/computing/Understanding-the-Four-Types-of-Artificial-Intelligence. html > accessed 5 April 2021.

15 'Written Comments on the WIPO Draft Issues Paper on Intellectual Property Policy and Artificial Intelligence' (WIPO, 2020) <https://www.wipo.int/export/sites/www/about-ip/en/artificial_ intelligence/call_for_comments/pdf/org_aippi.pdf> accessed 5 April 2021.

16 'An A.I. Just Outperformed 20 Top Lawyers (and the Lawyers Were Happy)'(Inc.com, 9 November 2018) <https://www.inc.com/jessica-stillman/an-ai-just-outperformed-20-top-lawyers-and-lawyerswere-happy.html> accessed 5 April 2021.

17 Case C-145/10 Eva-Maria Painer v Standard VerlagsGmbH and Others ECR 2011-00000.

18 Naruto $v$ Slater, 15-cv-04324-WHO, 2016, $5 \leq \mathrm{http}: / /$ cases.justia.com/federal/district-courts/california/ candce/3:2015cv04324/291324/45/0.pdf?ts=1454149106> accessed 6 June 2021.

19 US Copyright Office. Compendium of US Copyright Office Practices (3rd ed, 2021) <https://www. copyright.gov/comp3/docs/introduction.pdf> accessed 6 June 2021.

20 Burrow-Giles Litographic Co. v Napoleon Sarony [1884] 111 US 53, 58. 
rights. ${ }^{21}$ Thus, the practical interest is focused on the intellectual property protection of AI outputs: inventions and copyrighted works. The practice of protecting AI outputs through intellectual property is not extensive. The few decisions by national courts and patent offices concerning the registration of inventions form the basis of practice. The position of the patent offices is unanimously negative with regard to the possible identification of the creator as the AI itself. For illustration, this article will explore the individual decisions of the European Patent Office (EPO) and the German Patent and Trademark Office. In this context, the position of the courts is expected to be more difficult, as the formal requirements for a decision are not sufficient. In this context, the decisions of Chinese courts, which have explored the concept of authorship and 'human involvement', are particularly interesting.

The current position on the protection of AI outputs by patent law is negative. Such an approach was expressed in the EPO decision of 27 January 2020 on EP $18275163^{22}$ and the EPO decision of 27 January 2020 on EP $18275174 .{ }^{23}$ The decisions concern the refusal of the European patent applications EP 18275163 and EP 18275 174, in which an AI system called 'DABUS' was designated as the inventor. The EPO considered provisions of the European Patent Convention and the term 'inventor' and held that the term refers to a natural person, noting that this appears to be an internationally applicable standard and that various national courts have issued decisions to this effect. In the decision T 0161/18 of 12 May 2020, the EPO did not grant a patent on determining cardiac output with the aid of an artificial neural network. This decision points to a lack of descriptive sufficiency because a subject matter expert could not reproduce the training of an artificial neural network. In March 2020, the German Patent and Trademark Office also rejected two applications for inventions because the declared inventor was the AI system 'DABUS'. The reasoning for these decisions was due to sections 6, 37, and 63 of the German Patent Act, as well as Section 7 of the German Patent Ordinance, similarly stating that an inventor can only be a natural person. ${ }^{24}$

The possibility for the copyright protection of AI outputs is different from the point of view of the Chinese courts. On 2 April 2020, the Beijing Intellectual Property Court ruled in a case titled Gao Yang $v$ Youku. ${ }^{25}$ In this case, a sports camera attached to a hot air balloon automatically took videos of the earth's surface. When discussing the copyright issues, the court determined that although the camera was out of human control during the automatic overhead recording process, there still was a human intervention reflected in the preselection of a video recording mode, video display format, sensitivity, and other parameters of the camera. These parameters were considered to be set in advance; therefore, screenshots selected from the videos taken automatically by the camera constitute photographic works, and the unauthorised use of these pictures by others constitutes an infringement of the copyright of the plaintiff's photographic work. In Shenzhen Tencent $v$ Shanghai Yingmou, ${ }^{26}$ the Beijing Intellectual Property Court decided that computer-generated content is copyrightable, as

21 A Guadamuz, 'Do Androids Dream of Electric Copyright?' (n 5)

22 'Groundsforthedecision of 27January2020onEP18275163'(EuropeanPatentOffice, 2020)<https://register. epo.org/application?documentId=E4B63SD62191498\&number=EP18275163\&lng=en\&npl=false > accessed 7 April 2021.

23 'Groundsforthedecision of27January2020onEP18275174'(EuropeanPatentOffice, 2020)<https://register. epo.org/application?documentId=E4B63OBI2076498\&number =EP18275174\&lng=en\&npl=false > accessed 7 April 2021.

24 'Decisions relating to patent applications 102019129136.4 and 102019129136.4 ' (DPMA, 2020) $<$ https://register.dpma.de/DPMAregister/pat/register?lang=en\&fromSprachWechselLink > accessed 7 April 2021.

25 'Does China Back Copyrights for Automatic Photos from a Hot-Air Balloon?'(China Justice Observer, 2020)<https://www.chinajusticeobserver.com/a/does-china-back-copyrights-for-automatic-photosfrom-a-hot-air-balloon> accessed 7 April 2021.

26 'Court rules AI-written article has copyright' (The Supreme People's Court of the Peoples Republic of China, 2020) <http://english.court.gov.cn/2020-01/09/content_37531788.htm> accessed 7 April 2021. 
there is human intervention in created work. The Tencent Technology personnel used the company's own independently developed AI computer program, 'Dreamwriter', to write articles on sports, weather, and other issues. Shanghai Yingmou published one of the articles on its website, which was considered copyright infringement in the ongoing court decision. On 24 December 2019, the Nanshan District People's Court, Shenzhen, Guangdong Province, held that an article completed by an AI program is covered by the copyright of China. ${ }^{27}$ The most remarkable position in this court decision is that the court formed the final position on copyrightability through human intervention in the process of drafting the articles under question. On the one hand, this decision states a clear need for human presence in the creation of copyrightable works. On the other hand, the notion of 'human involvement' is broader than it previously appeared. The discussion concerning the cautions on the meaning of creators or authors apart from humans is premature, as autonomous AI has not developed yet. Until an AI has developed to a fully autonomous level, a human author has a chance to benefit from AI-generated works. In this context, the practice of EPO on patent claims with AI involvement could seem unsustainable, as it was pointed out that the claimants did not meet the formal requirements for obtaining the patent. Furthermore, the EPO is not authorised to decide on such uncertain and tricky legal issues.

In this regard, we can assume a quick conclusion that AI-generated objects in the US and $\mathrm{EU}$ are in the public domain, a position that is also supported by a number of academics. ${ }^{28}$

\section{LEGAL POLICY SOLUTIONS RELEVANT TO AI-GENERATED OBJECTS}

Obviously, IP policy relevant to AI is very topical, as some countries have already developed strategies on this issue. The UK was the first country that decided to grant computergenerated work copyright protection (s9(3) of Copyright, Designs and Patents Act 1988). ${ }^{29}$ Computer-generated work is defined as work generated by a computer in circumstances such that there is no human author of the work. The law considers the author to be the person by whom the arrangements necessary for the creation of the work are made and sets 50 years of protection. A similar legal regime is provided for in some other common law countries, e.g., India ${ }^{30}$ and Ireland. ${ }^{31}$ A. Guadamuz evaluates this model as successful and suggests it should be spread more widely. ${ }^{32}$ However, the sui generis right for AI-generated objects has not yet been explicitly established at the legislative level.

Ukrainian policymakers attempted to cover this issue in the Draft Law 'On copyright and related rights' (hereinafter, Draft Law). ${ }^{33}$ The Draft Law proposes, in Art. 35, 'the sui generis right to non-original objects, generated by computer program'. Such a proposition could be considered the awaited compromise between legal ignorance and the undermining of

27 B Zhou, 'Artificial Intelligence and Copyright Protection. Judicial Practice in Chinese Courts' (WIPO, 2020)<https://www.wipo.int/export/sites/www/about-ip/en/artificial_intelligence/conversation_ip_ ai/pdf/ms_china_1_en.pdf $>$ accessed 5 April 2021.

28 A Ramalho, 'Will Robots Rule the (Artistic) World? A Proposed Model for the Legal Status of Creations by Artificial Intelligence Systems' (2017) 21 Journal of Internet Law 12.

29 Copyright, Designs and Patents Act of United Kingdom (1988) <https://www.legislation.gov.uk/ ukpga/1988/48> accessed 14 June 2021.

30 Indian Copyright Act S. 2(d)(vi).

31 See Section 2(1) Irish Copyright and Related Rights Act 2000.

32 A Guadamuz, 'Do Androids Dream of Electric Copyright?' (2017) (n 5).

33 Draft Law of Ukraine 'On copyright and related rights' (2020) <https://www.me.gov.ua/Documents/ Detail?lang=uk-UA\&id=cf7b9e32-1995-4b66-995a-4ab3dcacla8f\&title=ProktZakonuUkrainiproAvto rskePravoISumizhniPrava\&isSpecial=true\#docAddCommentBox > accessed 7 April 2021. 
established conceptions of the author in copyright, particularly in the droit dateur system, but it is accompanied by a vast range of questions. Undoubtedly, the previous empiric inquiry should be undertaken to find justification for such a legal proposition.

The Draft Law defines a computer-generated object as a non-original object resulting from computer program activity without the direct involvement of an individual. It proposes to grant sui generis intellectual property rights to computer program rightsholders: authors of the computer program, their successors, and other subjects of copyright to whom the writs were assigned. The Draft Law provides sui generis rights as economic rights similar to copyright for 25 years, counted from the year of creation.

Based on the given definition, we can assume that the sui generis solution was chosen because computer-generated work is not considered original at all. That is, it does not reflect the author's own creation. At the same time, substantial investment can potentially be made into such computer-generated work; thus, it should be protected. The authors of the Draft Law did not express such a justification explicitly, but a short analysis could shed some light on this issue.

All the main intellectual property theories are anthropocentrically positioned, which means they include the direct involvement of humans. In this course, it is curious to consider 'whether deontological theories might preclude IP protection for other reasons where no human is sufficiently involved. ${ }^{34}$ Theories relevant to intellectual property rights, such as incentive theory, can be viewed from two approaches: general initiative theory and investment protection theory. The first approach makes the creation of new works conditional on the existence of intellectual property rights, while the second provides for the need to protect the investment made through intellectual property rights. The general theory of incentive has been questioned by some scholars on the grounds that exclusive rights themselves cannot replace market demand for the product of intellectual labour. ${ }^{35}$ It is difficult to disagree with this point because the psychological arguments in favour of a general theory of initiative are not convincing enough when there is no commercial gain from intellectual and creative results. In this regard, the protection of AI outputs by intellectual property can be justified by investment protection theory through the provision of a sui generis rights solution. The investment theory justifies the emergence of exclusive rights because of the need to protect the investment made. In case of the impossibility of protection by other means, e.g., technical ones, the legislative granting of exclusive rights for a limited period of time will help the owner to recover the investment and prevent illegal use. A similar approach has been used to protect non-original databases in the EU. The experience of the legislative implementation of the sui generis right will be considered in more detail below to identify positive developments for the Ukrainian regulation of AI outputs.

The sui generis right in intellectual property can be considered as an option for the legal regulation of subject matter that deviates from accepted concepts of intellectual property but is closely related. Some scholars have discussed the possibility of providing a national sui generis right for traditional knowledge as a solution. ${ }^{36} \mathrm{M}$. Halewood refers to sui generis intellectual property rights as a legal system of protection for knowledge that shares some characteristics with intellectual property law but which is different in unique ways to enable

\footnotetext{
34 J-A Lee, K-C Liu, R Hilty (eds.), Artificial Intelligence \& Intellectual Property (n 4).

35 R Hilty, J Hoffmann, S Scheuerer, 'Intellectual Property Justification for Artificial Intelligence' in J-A Lee, K-C Liu, R Hilty (eds.) Artificial Intelligence \& Intellectual Property (Oxford University Press 2021).

36 D Gervais, 'Traditional Knowledge \& Intellectual Property: A TRIPS-compatible Approach' (2005) 137 Mich St L Rev; M Halewood, 'Indigenous and Local Knowledge in International Law: A Preface to Sui Generis Intellectual Property Protection' (1999) 44 McGill L J 961 <https://lawjournal.mcgill.ca/wpcontent/uploads/pdf/7355599-44.Halewood.pdf $>$ accessed 8 April 2021.
} 
the protection of new subject matter. ${ }^{37}$ In the EU, under the Database Directive, sui generis right was granted for the protection of databases regardless of their originality, based on substantial investment. ${ }^{38}$ The concept of sui generis in EU copyright has emerged due to the legal structure in Dutch law - 'geschriftenbescherming' - which provides legal protection for non-original works. It is this approach that has been taken as the basis for determining the legal protection of non-original databases in the EU. In Dutch law, this construction is applied primarily to literary works and provides protection that is essentially similar to copyright protection. Historically, this unique right appeared to protect the rights of book publishers and was enshrined in the Copyright Act of the Netherlands of 1912, in particular, in Art. 10 (1), which provides for the protection of an open list of works. Thus, the wording of the article on 'protection of books, brochures, newspapers ... and other written works' gave rise to a contradictory diversion of the last two words. ${ }^{39}$ At the same time, this background should not be taken as the sole scope of sui generis right for databases, but rather as a historical illustration of the development. ${ }^{40}$ For now, the Database Directive is the only legal act that provides such sui generis intellectual property protection. In 1996, WIPO presented the draft of the 'Basic Proposal for the Substantive Provisions of the Treaty on Intellectual Property in Respect of Databases to be Considered by the Diplomatic Conference, ${ }^{41}$ which combined the EU and the US proposals concerning sui generis right in databases, although WIPO's draft treaty was never adopted.

The Database Directive does not explicitly connect sui generis to intellectual property rights, but an analysis of the Database Directive provisions leads to the conclusion that sui generis may be classified as an intellectual property right. Like copyright, exceptions, and limitations to sui generis rights are provided (e.g., a term of protection), and sui generis rights can be licensed and assigned. Yet, it should be pointed out that sui generis is not copyright. ${ }^{42}$ The adoption of the Database directive was driven by different factors. The EU stated that there is 'very great imbalance in the level of investment in the database sector both as between the Member States and between the Community and the world's largest database-producing third countries. ${ }^{43}$ Substantial investment was set as the key criterion for sui generis databases. The scope of substantial investment partially undiscovered in the Database Directive as an investment that may consist in the deployment of financial resources and/or the expending of time, effort, and energy. ${ }^{44}$ Also, the ECJ made it clear in its decision in Fixtures Marketing Ltd v. Oy Veikkaus that substantial investment must be construed in relative terms, first in relation to costs and their redemption, and secondly in relation to the scale, nature, and contents of the database and the sector to which it belongs. ${ }^{45}$ As the protection of the investment made by the owner of the AI is the main justification for legal protection, it would be appropriate to outline similar criteria for computer-generated objects. Another question is the scope of such investment in terms of AI. Since there is a practice based on the provisions of Database Directive application, the scope of investment in terms of AI-generated output could be considered to have its own

37 M Halewood, 'Indigenous and Local Knowledge in International Law' (n 36).

38 See Art. 7 of the EU Database Directive.

39 P Bernt Hugenholtz, 'Goodbye geschriftenbescherming!' (Kluwer Copyright Blog, 6 March 2013) <http:// kluwercopyrightblog.com/2013/03/06/goodbye-geschriftenbescherming/> accessed 7 April 2021.

40 Case C-46/02 Fixtures Marketing Ltd v Oy Veikkaus [2004] ECR I-10365.

41 World Intellectual Property Organisation, 'Basic Proposal for the Substantive Provisions of the Treaty on Intellectual Property in Respect of Databases to be Considered by the Diplomatic Conference' (1996) $<$ https://www.wipo.int/edocs/mdocs/diplconf/en/crnr_dc/crnr_dc_6.pdf> accessed 7 April 2021. I Stamatoudi, P Torremans, EU Copyright Law (Edward Elgar Publishing 2014) 320.

43 EU Database Directive, recital 11.

44 ibid, recital 40.

45 Fixtures Marketing Ltd v Oy Veikkaus (n 17). 
nature. Thus, the economic and legal research on this issue can form the basis for defining these criteria.

Despite the overall perspectives of the sui generis solution for AI output, there are other misleading sections in the Draft Law of Ukraine. From the given definition, it seems that the right to a computer-generated object covers the concept of fully autonomous AI, as indicated by the absence of direct human participation in its creation. Although, from time to time, information appears in the media that an AI created a new work, such as a song or a picture, ${ }^{46}$ these works were generated based on information created by a human. Some AI-generated works that follow the style of a certain artist are possible only thanks to machine learning based on data created by that particular artist. However, such works could be considered to have been created with the sufficient involvement of a human, not independently. This position partially coincides with the decision in Shenzhen Tencent $v$ Shanghai Yingmou, which was discussed above. Modern technology does not yet allow us to recognise the existence of this type of AI. Thus, the most technologically advanced machines of our era are little more than faithful agents of the humans who design or use them. ${ }^{47}$

The Concept of Recodification of the Civil Code of Ukraine ${ }^{48}$ also addresses AI questions in brief. It proposes to amend a list of general principles of civil law with the following provisions: 'conscious, responsible human interaction with autonomous robots and AI'; adjusting the tort system with provisions on 'compensation for damage caused by AI'. Notions 'autonomous work' and 'artificial intelligence' ${ }^{49}$ are included in the extended list of objects of civil rights, which indicates that the authors of the Draft Concept consider AI as an object dependent on humans.

\section{CONCLUDING REMARKS}

The Draft Law does not define the specific type of subject matter for which legal protection can be granted. As previously analysed, only the economic value of computer-generated objects justifies this special type of protection. In this regard, more economic research is needed on the need for protection for specific computer-generated content. Otherwise, the adoption of the proposed provisions as they are could lead to excessive protection, e.g., of translations made by AI-based platforms (e.g., the Google translate platform).

Despite the overall promise of the legal regulation of AI-generated output through a sui generis solution, the analysed legislative initiative is premature due to various factors: the lack of previous economic and legal empirical research to justify protection; the need for additional legislative refinement of draft provisions. Otherwise, the adoption of such a Draft Law could result in unpredictable consequences for both intellectual property law and the creative industries. The sui generis right solution for AI output is promising since it responds to few legal issues, but more is yet to come.

46 'The first piece of AI-generated art to come to auction' (christies.com, 12 December 2018) <https:// www.christies.com/features/A-collaboration-between-two-artists-one-human-one-a-machine-9332-1. aspx> accessed 7 April 2021.

47 JC Ginsburg, LA Budiardjo, 'Authors and Machines' (2019) 34 Berkeley Technology Law Journal.

48 AS Dovgert et al, Concept of Renovation of Civil Code of Ukraine (ArtEk 2020).

49 ibid, chapter III. 


\section{References}

1. Anantrasirichai N, Bull D Artificial Intelligence in the Creative Industries: A Review (2020).

2. Dovgert AS et al, Concept of Renovation of Civil Code of Ukraine (ArtEk 2020).

3. Gervais D, 'Traditional Knowledge \& Intellectual Property: A TRIPS-compatible Approach' (2005) 137 Mich St L Rev .

4. Ginsburg JC, Budiardjo LA, 'Authors and Machines' (2019) 34 Berkeley Technology Law Journal.

5. Guadamuz A, 'Do Androids Dream of Electric Copyright?' (2017) IPQ 169.

6. Halewood M, 'Indigenous and Local Knowledge in International Law: A Preface to Sui Generis Intellectual Property Protection' (1999) 44 McGill L J 961.

7. Hilty R, Hoffmann J, Scheuerer S Intellectual Property Justification for Artificial Intelligence' in J-A Lee, K-C Liu, R Hilty (eds.) Artificial Intelligence \& Intellectual Property (Oxford University Press 2021).

8. Hintze A, 'Understanding the Four Types of Artificial Intelligence', Cloud and Computing (2016) <https://www.govtech.com/computing/Understanding-the-Four-Types-ofArtificial-Intelligence.html>.

9. Lee J-A, Liu K-C, Hilty R (eds.), Artificial Intelligence \& Intellectual Property (Oxford University Press 2021).

10. Morhat PM 'The Legal Personality of Artificial Intelligence in Intellectual Property Law: Civil Law Issues' (Dr. Sc. (Law) thesis, Russian State Intellectual Property Academy 2018).

11. Ramalho A, 'Will Robots Rule the (Artistic) World? A Proposed Model for the Legal Status of Creations by Artificial Intelligence Systems' (2017) 21 Journal of Internet Law 12.

12. Spindler G, 'Copyright Law and Artificial Intelligence' IIC 50, 1049-1051 (2019). https://doi. org/10.1007/s40319-019-00879-w

13. Stamatoudi I, Torremans P, EU Copyright Law (Edward Elgar Publishing 2014).

14. Wang P, 'On Defining Artificial Intelligence' (2019) 10 (2) Journal of Artificial General Intelligence 1-37. doi: 10.2478/jagi-2019-0002 